Research Article

\title{
Experimental Study on the Impact of Landslide-Generated Waves against Wharf Pile
}

\author{
Ping Mu $\mathbb{D}^{1,2}$ Pingyi Wang $\mathbb{D}^{1,2}$, Linfeng Han $\mathbb{D}^{1},{ }^{3}$ Jie Zhang, ${ }^{1,2}$ and Meili Wang ${ }^{4}$ \\ ${ }^{1}$ National Engineering Technology Research Center for Inland Waterway Regulation, Chongqing Jiaotong University, \\ Chongqing 400074, China \\ ${ }^{2}$ Co-Established by Province and Ministry, \\ Key Laboratory of Water Conservancy and Transport Engineering of Education Ministry, Chongqing Jiaotong University, \\ Chongqing 400074, China \\ ${ }^{3}$ School of Civil Engineering, Chongqing Jiaotong University, Chongqing 400074, China \\ ${ }^{4}$ School of Architecture and Urban Planning, Chongqing Jiaotong University, Chongqing 400074, China
}

Correspondence should be addressed to Pingyi Wang; py-wang@163.com

Received 16 June 2020; Revised 24 September 2020; Accepted 24 October 2020; Published 11 December 2020

Academic Editor: Rafael J. Bergillos

Copyright $(92020$ Ping Mu et al. This is an open access article distributed under the Creative Commons Attribution License, which permits unrestricted use, distribution, and reproduction in any medium, provided the original work is properly cited.

\begin{abstract}
Landslide-generated waves have caused great catastrophic damage to the infrastructure, e.g., dam and wharf, because of the extreme loading in the reservoir area, while the wharf pile is rarely designed to withstand the loading associated with landslidegenerated waves. This experimental study was conducted in a generalized 3D basin to simulate the waves generating process and explore the impact of the dynamic pressure process on the wharf pile. As the phenomenon that landslide-generated impulse waves impacted on the wharf pile in the form of dynamic pressure, the distribution pattern of the dynamic pressure along the water column was analyzed and revealed specifically. The results indicate that the dynamic pressure was constant below the water surface along the vertical direction and its magnitude was correlated with the wave amplitude as well as wave celerity. On this basis, a multivariate dimensionless analysis was implemented, and the empirical formulas for the dynamic pressure were established. Furthermore, the total force acting on the wharf pile was given. From a practical perspective, these findings could offer guidance to prevent the damage of the impulse wave pressure on the wharf pile.
\end{abstract}

\section{Introduction}

Impulse waves impacting into reservoirs is a typical secondary natural disaster formed after the landslide enters into the water, and its damage often significantly exceeds the landslide itself [1]. As a worldwide hazard, landslide-generated impulse wave has resulted in catastrophic disaster and caused great losses of life and property, destruction of the infrastructure in wharf, and vast devastation even overturn to the ships. In this vein, taking the famous Vajont impulse wave event as a typical case, almost 2000 persons were killed and the downstream city of Longarone was fully destroyed [2].

Hence, to solve this predicament, the topic of landslides generated impulse waves in reservoirs has been attracting worldwide attention over the past decades. From the perspective of research content, as recently summarized by $\mathrm{Mu}$ et al. [3], this extant literature mainly focused on the impulse wave generation $[4,5]$, near field propagating wave characteristics [6-8], and offshore wave runup [9-11], while little attention was paid to the exposed wharves and other buildings. To a large extent, with the development of the ports, the wharf becomes more important for the safe operation of the reservoir compared with other buildings (e.g., bank slope and breakwater) and is plagued with more serious hazardous consequences when encountering the impulse wave event $[12,13]$. Theoretically, the damage of impulse waves to the wharf is mainly attributed to the total force, which is caused by hydrodynamic and hydrostatic pressure. Since the hydrostatic pressure theory has been 
already developed maturely, the force analysis of conventional design loads on infrastructure could be conducted well. Furthermore, the wind load and the tide load as the extreme loading have been considered generally in the wharf design, but the extreme loading associated with landslidegenerated impulse wave on the wharf is basically ignored [14]. Obviously, this omission will bring a series of risks to the management and operation of wharves. Therefore, as an identified knowledge gap, the hydrodynamic pressure of landslide-generated impulse wave exerted on the wharf is an important issue to address.

In view of this case, taking the Three Gorges Reservoir (TGR) in China as a representative case, exploring the hazardous impact of impulse wave pressure on the exposed wharves is not only important but also necessary. As one of the largest artificial reservoirs worldwide, the TGR has being faced with the serious natural hazard of impulse waves, whilst the number of wharves has increased significantly since it impounded in 2003 [15]. Simultaneously, more than 5300 landslides happened because of the impoundment and water-level fluctuation between $145 \mathrm{~m}$ and $175 \mathrm{~m}$ [16], welldocumented events include the impulse waves induced by Qianjiangping landslide on 14 July, 2003 [17], Gongjiafang landslide on November, 2008 [18], and the Hongyanzi landslide-generated impulse waves on June 24, 2015 [19]. Under this situation, to effectively prevent the hazard, it is very urgent to explore the hazardous impact of landslidegenerated impulse wave pressure on the exposed wharves in the TGR. Furthermore, given that high-pile wharf is the most popular type in the TGR [12], this study is further limited to the wharf pile to improve the effectiveness of research.

In view of these conditions, this study aims to examine the impact of landslide-generated impulse waves against the wharf pile in the TGR. Meanwhile, the impact on the wharf pile mainly contributes to the dynamic wave pressure, which is essentially caused by the fluctuation of water level (namely, impulse wave) [14]. Consequently, the detailed objectives of this paper are (1) to simulate the waves generate process and explore the characteristics of landslide-generated impulse at the wharf; (2) to conduct the dynamic pressure process and distribution along the water depth; (3) to reveal the relationship between the dynamic pressure and wave amplitude as well as wave velocity and further deduce the dynamic pressure formulas of the impulse waves and the total force acting on wharf pile.

\section{Experimental Setup}

2.1. Wave Generation. Due to some features such as suddenness and short duration, the data of landslide-induced impulse waves are scarce on field measurements $[3,20]$. To make up for the lack of data, an experimental approach is therefore adopted to simulate and analyze the process of landslide-generated impulse waves in this paper. The scaled physical experiment has been widely used to study the landslide-related impulse waves [21-23], because it can make the phenomenon quite realistic. Following previous studies [24,25], the present experiments were conducted in a

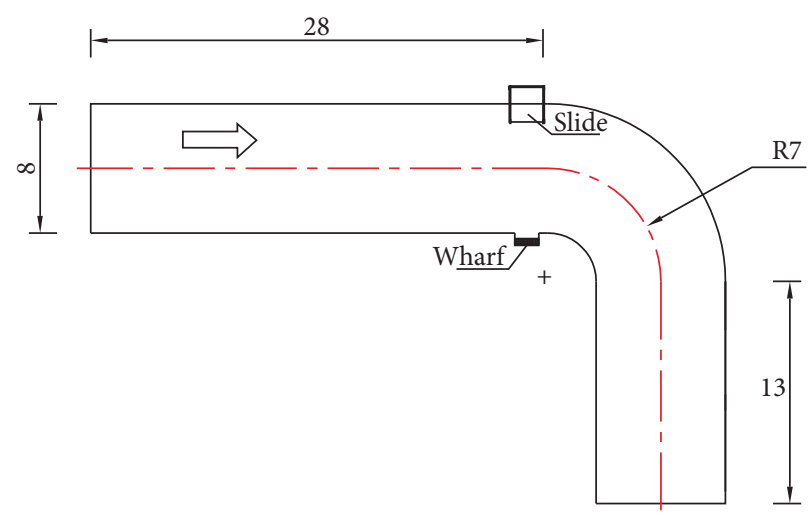

Figure 1: Plane layout of the wave basin; geometrical measurements were in $\mathrm{m}$.

3D wave basin with a scale of $1: 70$, generalized from the prototype of the Jiangnan tuokou wharf reach, which was a typical curved reach existing in the upper Yangtze River (see Figure 1). Specifically, the total length of the basin was $48 \mathrm{~m}$, the upstream and downstream straight were $28 \mathrm{~m}$ and $13 \mathrm{~m}$, respectively. The radius of curvature for the intermediate portion was $7 \mathrm{~m}$. The cross-section of the basin was trapezoidal, the bottom was $2.94 \mathrm{~m}$, and the slopes in concave bank and convex bank were $33^{\circ}$ and $20^{\circ}$, respectively. The details are illustrated in Figure 2.

The waves were generated by a gravity type wave maker at the concave bank of the basin. The system of wave maker, including landslide, chute, wire mesh, and chain hoist , described specifically by $\mathrm{Mu}$ et al. [26], allowed for predefining the slide geometry and the slide impact angle. In addition, the chute could restrict the granular concrete blocks from an instant collapse of the slide before entering the water basin. Field survey indicates that there are primarily rocky block rockfall or slide and the disintegrating structure rock mass failure that have failed or have the potential to fail in the TGR, which generates or may generate impulse waves [27, 28]. In this paper, we focus on the latter type. The landslides were modeled by the granular concrete blocks containing five various geometric sizes (labelled as (a), (b), (c), (d), and (e)), as illustrated in Figure 3, allowing for similarity and deformability as reported by Han and Wang [29]. Compared to these granular materials, such as artificial material $\left(\mathrm{PP}-\mathrm{BaSO}_{4}\right)$ [21], spherical glass beads, and nonspherical aquarium sand [30], the present slides modeled by quadrangular concrete blocks, with a density of $2,500 \mathrm{~kg} /$ $\mathrm{m}^{3}$, were more similar to the happened or potential landslides in the TGR.

Tested landslide models with nine different sizes, including a constant slide length $1.00 \mathrm{~m}$, a slide width $0.50 \mathrm{~m}$, $1.00 \mathrm{~m}$, and $1.50 \mathrm{~m}$, and a slide thickness $0.20 \mathrm{~m}, 0.40 \mathrm{~m}$, and $0.60 \mathrm{~m}$, were carried out by adjustment of the sliding chute geometrical shape. The slide length with a constant $l=1 \mathrm{~m}$ was deemed to be appropriate based on the result that the slide length has a slight influence on the primary wave reported by Wiegel [31]. This chute allowed for predefining the slide geometry, including a slide width $0.50 \mathrm{~m}, 1.00 \mathrm{~m}$, and $1.50 \mathrm{~m}$ and a slide front edge allowing it to reach 


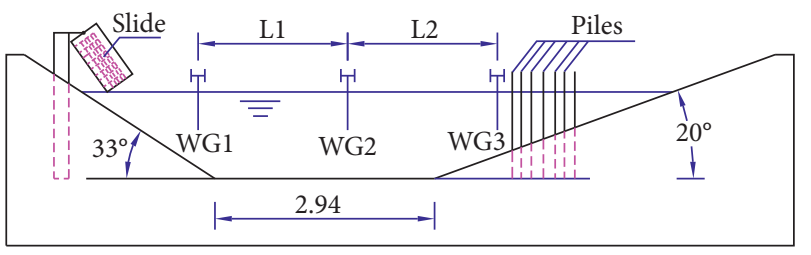

Figure 2: The detailed setup of three wave gauges.

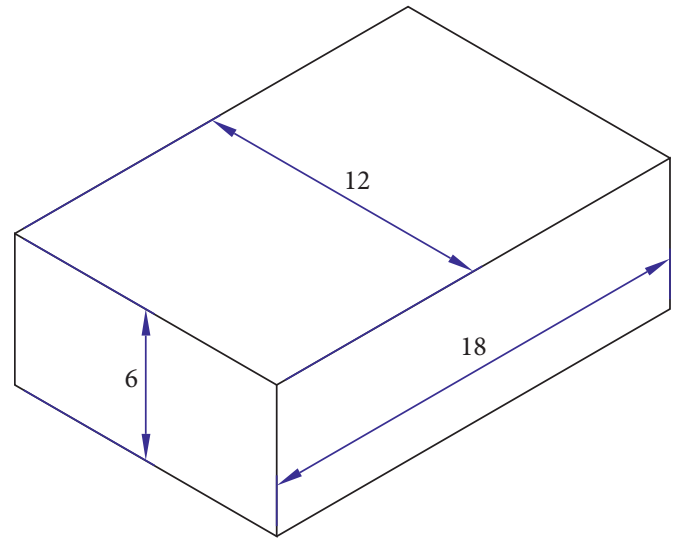

(a)

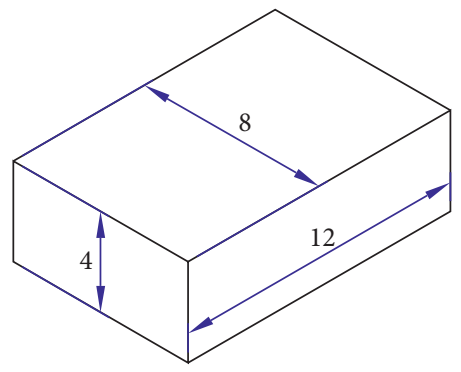

(b)

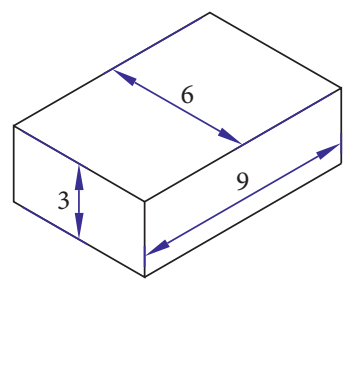

(c)

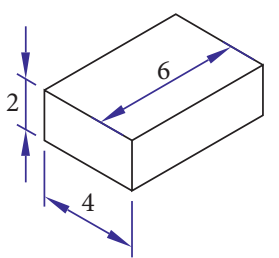

(d)

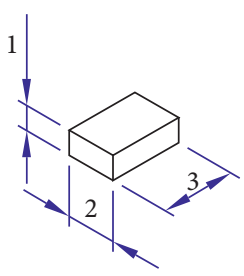

(e)

FIGURE 3: Sizes of concrete blocks; geometrical measurements were in $\mathrm{cm}$.

different still water depths, as well as a slide impact angle with any value. A flexible wire mesh was placed in front of the sliding chute to restrain the concrete blocks before the trials. When everything was ready, for instance, the water was still and the measuring equipment had been already debugged, the motion of landslide was triggered and accelerated due to gravity into the water body after suddenly manual release for the wire mesh. Impulse wave was generated from the moment that slide entered into the water body until the cessation of its underwater motion. Moreover, the blocks would be brought up before each experiment to remain in the same initial experimental conditions.

2.2. Wharf Model. Apart from the induced impulse wave, subsequently, we will focus on the model of wharf. As emphasized in Section 1, the generalized wharf used in the present study was "high-pile," and its structure was assumed as "rigid," fixed in the opposite bank of the landslide with a distance $6.37 \mathrm{~m}$ along the axis. The length and width of the wharf were $1.50 \mathrm{~m}$ and $0.43 \mathrm{~m}$, respectively. These piles with the diameter $2.28 \mathrm{~cm}$, line spacing $10 \mathrm{~cm}$, were made by plastic pipes, as shown in Figure 4.
2.3. A Comprehensive Experimental Design. The sliding chute allowed for any angle from 0 to 80 degrees, but only 20, 40 , and 60 degrees were considered in this study based on the field investigation of the distribution of landslide angle in TGR, where the landslide impact angles were from 20 to 60 degrees, and the average value was 36 degrees. Landslidegenerated impulse waves have great differences under different water level conditions [32]. Since the impoundment of the TGR in 2003, the water level fluctuated periodically between $145 \mathrm{~m}$ asl and $175 \mathrm{~m}$ asl $[15,20]$, so $145 \mathrm{~m}$ asl, $155 \mathrm{~m}$ asl, and $175 \mathrm{~m}$ asl were selected as the experimental water levels. Based on the investigated cross-section and the bottom elevation of the prototype, the water depths in the physical model corresponded with these three water levels can be calculated according to geometric similarity, which were $0.74 \mathrm{~m}, 0.88 \mathrm{~m}$ and $1.16 \mathrm{~m}$, respectively. Moreover, the water depths conform to the criterion of thumb $h \geq 0.20 \mathrm{~m}$ to rule out considerable scale effects on the maximum wave amplitude of subaerial landslide-generated impulse waves, suggested by Heller et al. [33].

Based on the above analysis, the experiments contained four factors: slide thickness $(s)$, slide width $(w)$, slide impact angle $(\alpha)$, and still water depth $(h)$. More impulse wave sets were needed to understand the relationship between impulse 


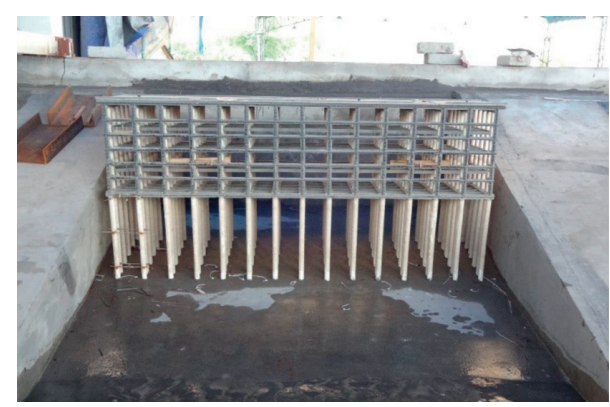

FIgURE 4: The layout of wharf in the test.

waves and pressure, so three levels were chosen for each factor, as shown in Table 1. A comprehensive experimental design with all of the factors and combinations was chosen; therefore, $3^{4}=81$ trials have been conducted. Moreover, each test with identical controlled variables was repeated twice.

In fact, there was an independent parameter called the slide impact velocity at the water-entry place, which was influenced by the slide impact angle. This is because the front of landslide models was adjusted just to touch the surface of water, and the slide length was kept constant, so the release height above water increased with the increase of $\alpha$ in the basin. As a result, the slide impact velocity $\left(v_{s}\right)$ was inconstant with different slide impact angles. The previous experimental study by Evers et al. [5] showed that $v_{s}$ was significant for impulse wave characteristics, especially the first wave crest amplitude and wave trough amplitude. Hence, the slide movement process was recorded in videos by a high-definition camera, and $v_{s}$ could be estimated. It is important to note that the drop height of underwater increased with the increase of $h$. Therefore, the slide impact angle and the still water depth could exert a positive influence on the kinetic slide energy, which could be ultimately conversed to wave energy. Finally, the experimental parameters were expressed as dimensionless ones including the relative slide length $(L)$, relative slide width $(W)$, relative slide thickness $(S)$, relative slide volume $(V)$, the slide Froude number $(F)$, and the slide impact angle. The details of these dimensionless experimental parameters are summarized in Table 2.

2.4. Experimental Measurements. The main measurement instruments include the wave gauges to measure the water surface elevations in the wave propagation direction and pressure sensors to determine the impulse wave pressure on the wharf pile.

In the wave basin, 24 wave gauges with an identification number from 1 to 24 were installed in the generation and propagation zones. The wave gauges with an accuracy of $\pm 1.0 \mathrm{~mm}$ and a sampling frequency of $50 \mathrm{~Hz}$ are developed by Southwest Water Transport Engineering Research Institute. However, the data from all the wave gauges are beyond the scope of this paper, which focus on the generation and attenuation of the impulse waves and will be investigated in future work by the authors. Only the data from three wave gauges (labelled as WG1, WG2, and WG3
TABLe 1: Three levels of parameters.

\begin{tabular}{lcc}
\hline Parameters & Dimension & Three levels \\
\hline$s$ & $\mathrm{~m}$ & $0.20,0.40,0.60$ \\
$w$ & $\mathrm{~m}$ & $0.50,1.00,1.50$ \\
$\alpha$ & Degree & $20,40,60$ \\
$h$ & $\mathrm{~m}$ & $0.74,0.88,1.16$ \\
\hline
\end{tabular}

TABLE 2: Overview of experimental quantities.

\begin{tabular}{lc}
\hline Dimensionless experimental parameters & Test range \\
\hline$\prod_{1}=L=l / h$ & $0.862 \sim 3.436$ \\
$\prod_{2}=W=w / h$ & $0.431 \sim 3.000$ \\
$\prod_{3}=S=s / h$ & $0.121 \sim 0.983$ \\
$\prod_{4}=F=v_{s} /(g h)^{1 / 2}$ & $0.178 \sim 0.993$ \\
$\prod_{5}=V=l w s / h^{3}$ & $0.064 \sim 7.200$ \\
$\prod_{6}=\alpha$ & $20 \sim 60$ degrees \\
\hline
\end{tabular}

in Figure 2) along the slide axis direction were used according to the objective needs of the present research.

WG1 was placed near the point where the slide entered water to record the impulse wave profiles and was moved to adopt different water depths based on the preliminary tests, and it was used to record the initial wave. WG3 was fixed near the wharf to investigate the characteristics of landslidegenerated impulse waves. WG2 was between WG1 and WG3. The spacing between adjacent wave gauges was a variable of water depth, as presented in Table 3.

The impulse wave pressure was measured by pressure sensors (CYG1145T) with an accuracy of $\pm 1.0 \mathrm{~Pa}$ and a sampling frequency of $500 \mathrm{~Hz}$. The wave pressure sensors at equal intervals were placed on the middle wharf pile, labelled as WPS1 to WPS3, from the bottom upward to static water surface. However, the water depth was a governing parameter and not a constant, so the intervals were not the same in different water depths. WPS1 was fixed at the same location, and WPS3 was used to record the wave pressure at the surface of water. When the water depths were $0.74 \mathrm{~m}$, $0.88 \mathrm{~m}$, and $1.16 \mathrm{~m}$, the intervals between two adjacent wave pressure sensors were $0.345 \mathrm{~m}, 0.415 \mathrm{~m}$, and $0.555 \mathrm{~m}$, respectively (see Figure 5).

However, the signals collected by wave pressure sensors were voltage values. In order to acquire the voltage-pressure curves, the experiments between wave pressure and voltage were tested three times. The mean values were adopted as the calibration results.

\section{Results and Discussion}

3.1. Wave Generation Process. The slide began to impact into the water body after sudden manual release for the wire mesh, while waves including jetflow and impulse waves were generated. A sequence of pictures was extracted from the video, as shown in Figure 6.

In Figure 6(a), only a few concrete blocks fell into water at the moment of manual release for the wire mesh, and the first jetflow was generated. As a number of concrete blocks plunged into the basin, the first jetflow was further intensified, see Figure 6(b). The first jetflow surged forward and 
TABLE 3: The distance parameter.

\begin{tabular}{lcc}
\hline Still water depth $(\mathrm{m})$ & L1 $(\mathrm{m})$ & L2 $(\mathrm{m})$ \\
\hline 0.74 & 2.00 & 1.50 \\
0.88 & 2.00 & 2.50 \\
1.16 & 2.00 & 2.50 \\
\hline
\end{tabular}

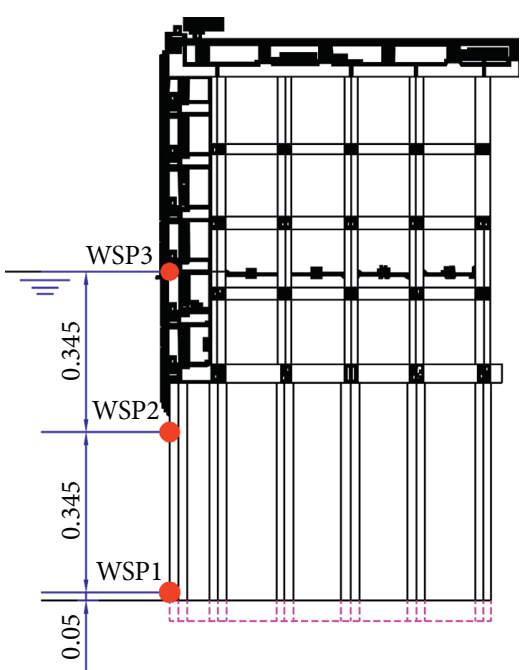

(a)

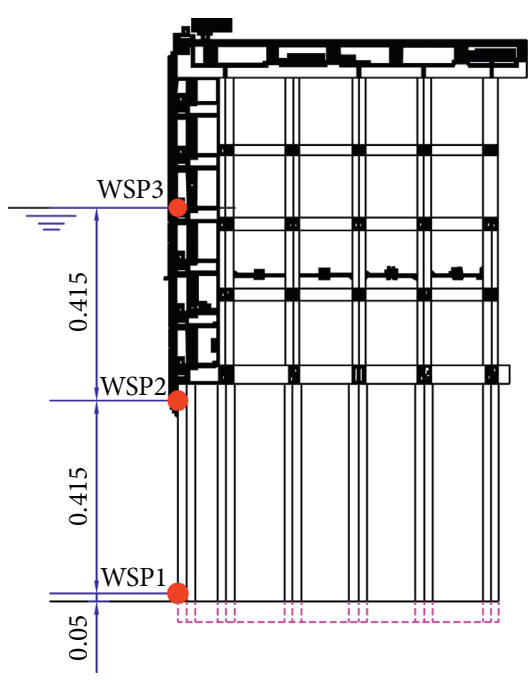

(b)

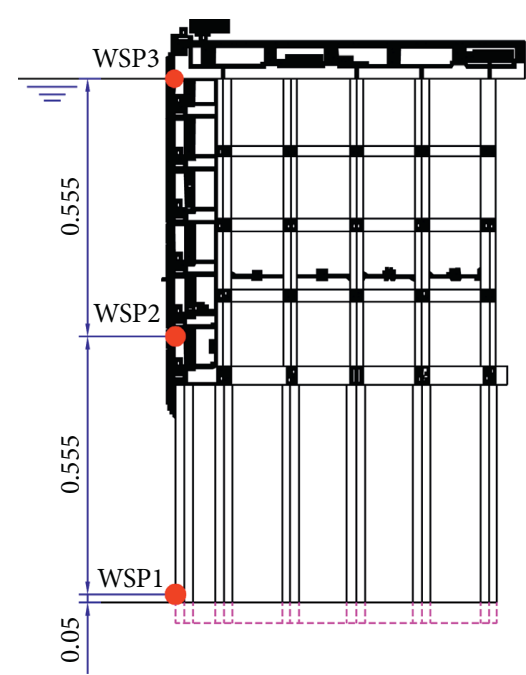

(c)

FIGURE 5: The experimental setup of three wave pressure sensors at different water depths.

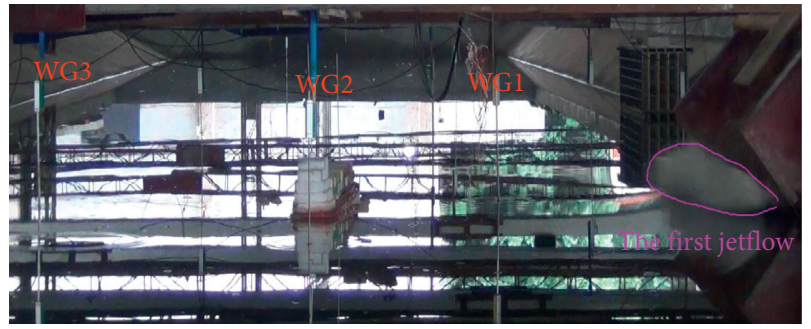

(a)

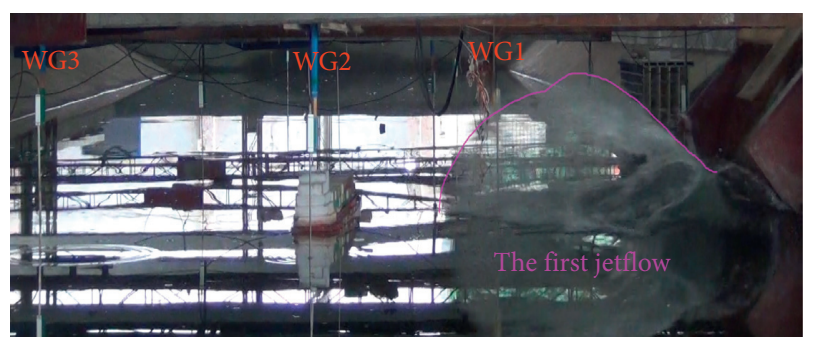

(c)

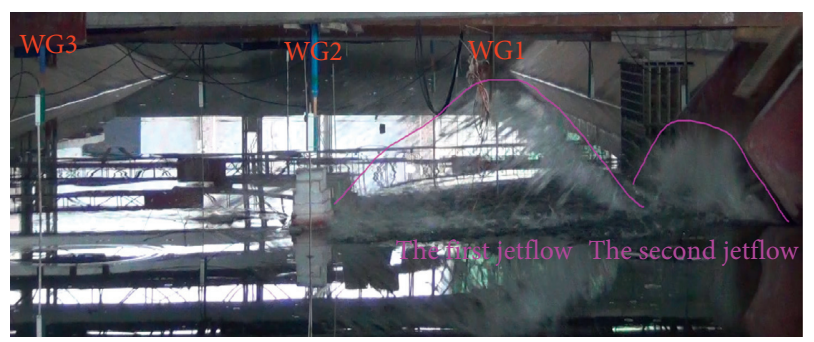

(e)

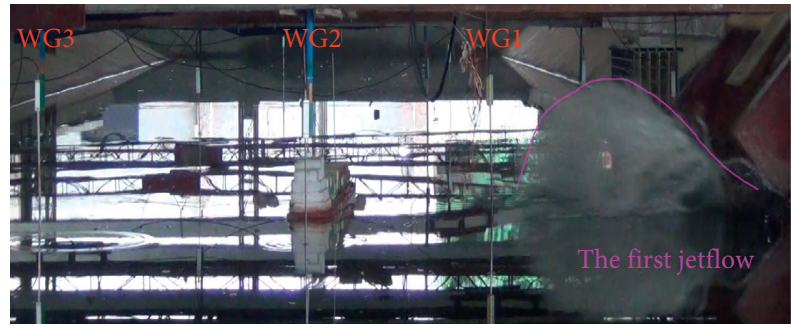

(b)

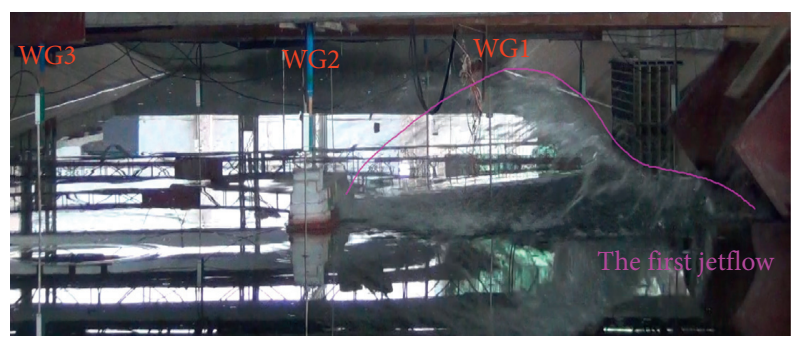

(d)

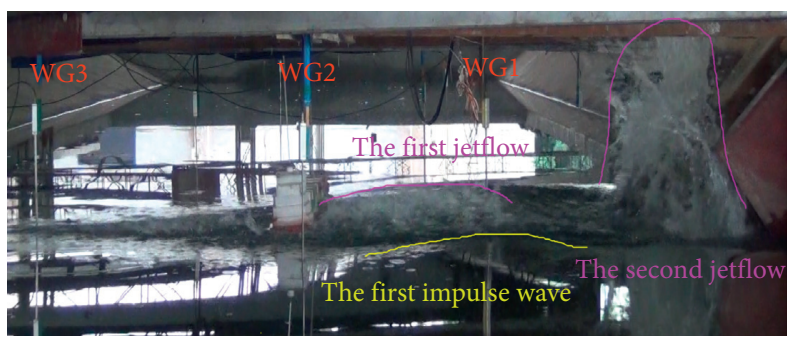

(f)

Figure 6: Continued. 


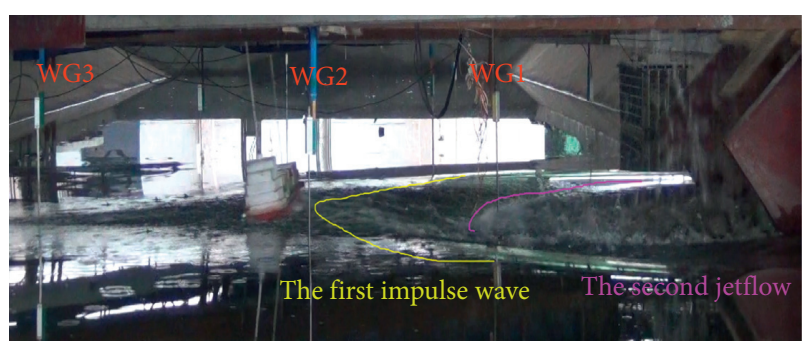

(g)

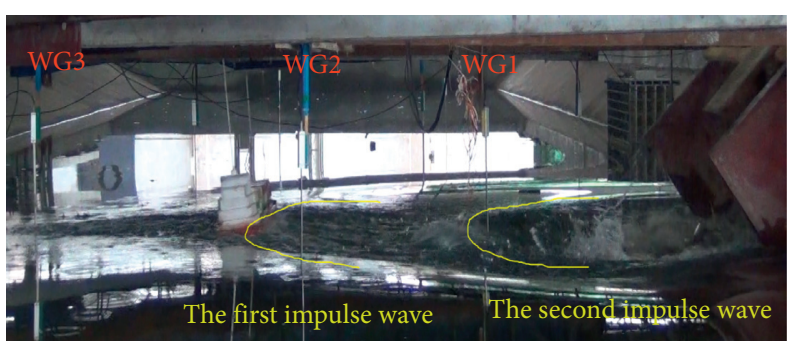

(h)

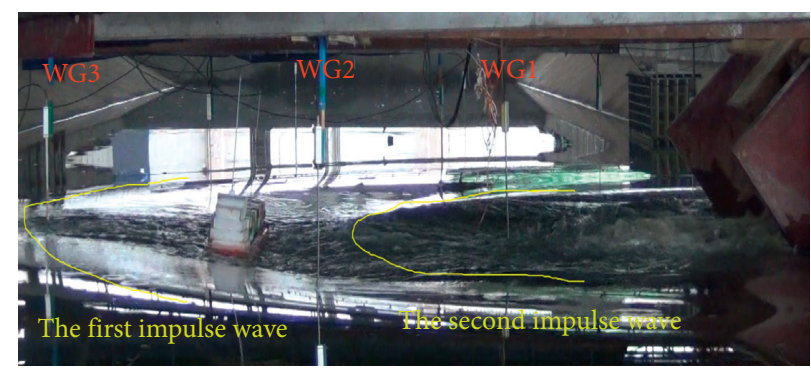

(i)

Figure 6: The process of waves generation from test no. 15 with $l=1.0 \mathrm{~m}, w=1.0 \mathrm{~m}, s=0.6 \mathrm{~m}, h=0.74 \mathrm{~m}$, and $\alpha=40$ degrees.

fell down in the force of inertia and gravity, and an aerated water tongue formed quickly, as shown in Figures 6(c) and 6(d). Immediately followed by the second jetflow, and the first jetflow faded away and the second jetflow strengthened gradually, simultaneously the first impulse wave came into being, as shown in Figures 6(e) and 6(f). After that, the second jetflow disappeared and the second impulse wave was generated, as presented in Figures $6(\mathrm{~g})$ and $6(\mathrm{~h})$. The first and second impulse waves propagated upstream, downstream, and the opposite bank in the basin, in Figure 6(i) the first impulse wave had been out of the video recorded by the camera. In addition, the heights of both the first and second jetflow were much larger than the impulse wave crest; the phenomena were also found by Tan et al. [14], who carried out the tests in generalized model. From a disastrous perspective, the destructive intensity of jetflow was much greater than the impulse wave, but the influence range was smaller than the impulse wave.

Furthermore, it can be drawn that the jetflow reached its maximum at the location of WG1, and almost disappeared at the position of WG2. However, the jetflow could not be captured in WG3. That is to say, the record of WG3 was only the water level by the static water plus the impulse wave. For the impulse wave, similarly, the wave amplitude of the primary wave was highest near the point where the slide impacted the water and became lower with the distance of propagation increasing. When these impulse waves arrived at the wharf, the amplitude of the leading waves was relatively smaller than that in the water-entry place.

Besides the above pictures from the video, these three wave gauges also recorded the water-level processes at the locations of WG1, WG2, and WG3, as shown in Figure 7.

The first impulse wave crest amplitude recorded by WG1 was the largest, and the one at the location of WG2 was secondly larger. However, the wave crest amplitude of WG3 was the least. It could be attributed to two reasons, one was the influence of jetflow, which had a great effect at the site of WG1 but almost little impact at WG3, and the other was that the wave amplitude was generally attenuated because of the dispersion and damping when propagating [32].

3.2. Dynamic Pressure Process and Distribution. The hydrodynamic pressure was essentially caused by the impulse wave and jetflow, characterized by high splash and dynamic flow around the structure [34]. However, the wharf pile was far from the entry point of the slide and the jetflow could not reach here. Therefore, the hydrodynamic pressure on the wharf pile was only the dynamic pressure generated by the impulse wave. Through the data analysis of wave pressure sensors, an interesting phenomenon has been discovered, which was that the dynamic pressure processes recorded by WPS1, WPS2, and WPS3 were almost identical. Test no. 81 was selected as an example, and the dynamic pressure processes are shown in Figure 8.

In Figure 8, it is not hard to find that the wave pressure profiles recorded by WPS1, WPS2, and WPS3 were almost synchronous. For example, the dynamic pressures of WPS1, WPS2, and WPS3 simultaneously reached their maximum values at about $30.5 \mathrm{~s}$. Similarly, the minimum negative dynamic pressures recorded by the three pressure sensors appeared at the same time (approximate $31.5 \mathrm{~s}$ ). In addition, the dynamic pressure of the impulse waves on the wharf pile came to being when the first impulse wave arrived, and the first dynamic pressure was also the highest one.

Subsequently, the distribution of wave pressure on the pile along water depth would be explored and revealed. From the perspective of safety, the maximum dynamic pressure would threaten the wharf pile. Specifically, the maximum positive dynamic pressure made the wharf pile 

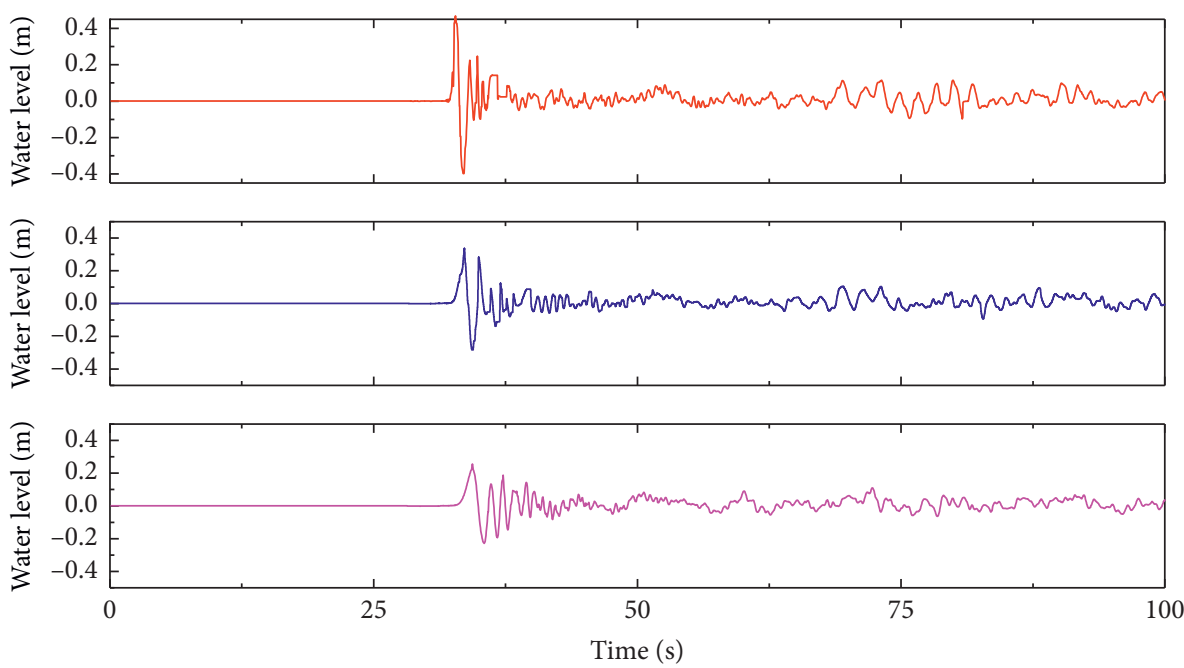

- WG1

- WG2

- WG3

FIGURE 7: The water-level processes recorded by three wave gauges.
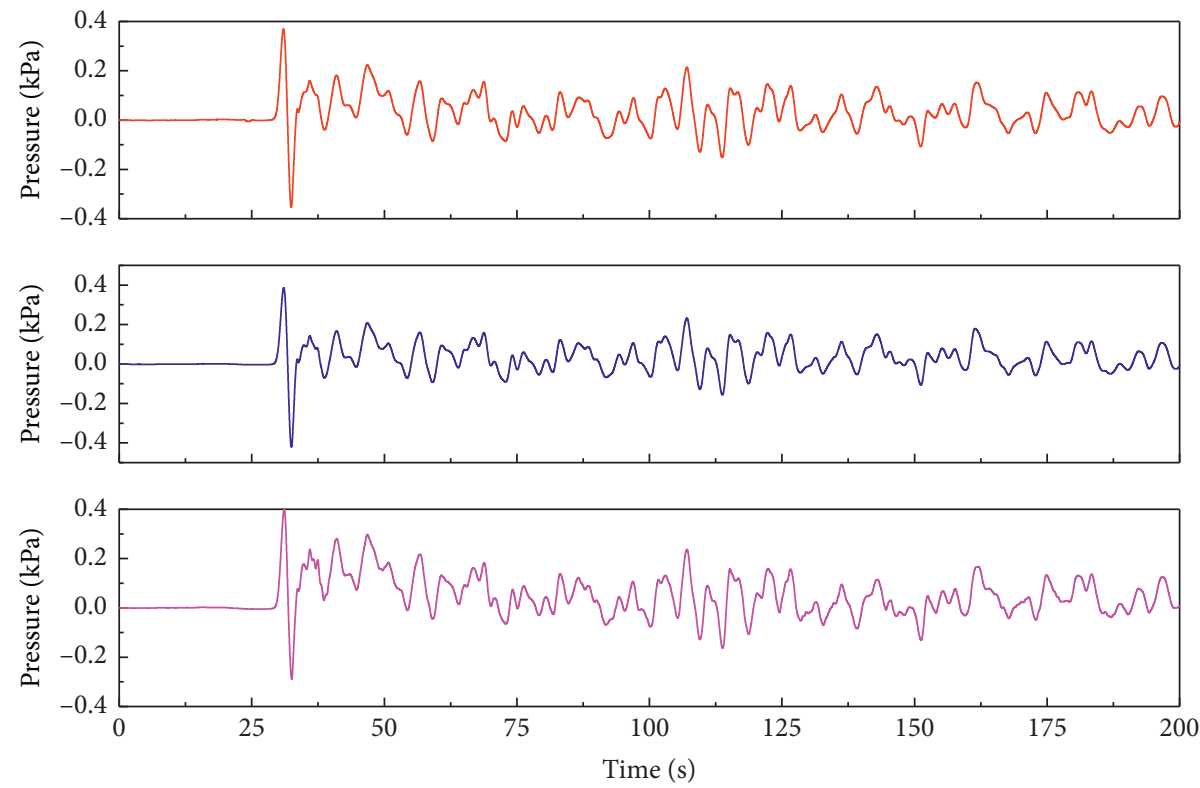

WPS3
WPS2
WPS1

Figure 8: The dynamic pressure processes from test no. 81 , with $l=1.0 \mathrm{~m}, w=1.5 \mathrm{~m}, s=0.6 \mathrm{~m}, h=1.16 \mathrm{~m}$, and $\alpha=60^{\circ}$.

endure the largest total pressure, and the minimum negative dynamic pressure may cause negative pressure on the wharf pile. As mentioned above, the first dynamic pressure was always the most significant, hence both the first maximum positive dynamic pressure $\left(P_{c}\right)$ and the first minimum negative dynamic pressure $\left(P_{t}\right)$ were adopted to explore the regularity of dynamic pressure distribution. Except for lacking data in all tests, $P_{c}$ and $P_{t}$ at different still water depths are plotted in Figure 9. In general, the absolute value of positive dynamic pressure was greater than the negative dynamic pressure under the same experimental conditions, and the former had a more regular distribution than the latter.

On the whole, the dynamic pressure was almost constant along the vertical direction under the still water level. It means that landslide-generated wave energy not only happened on the surface but also throughout the whole water, and the dynamic pressure was almost the same from 


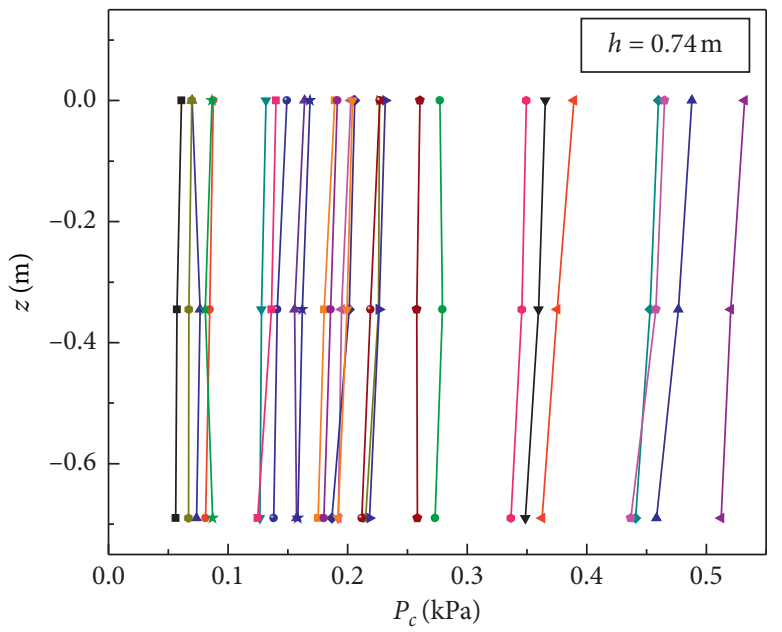

(a)

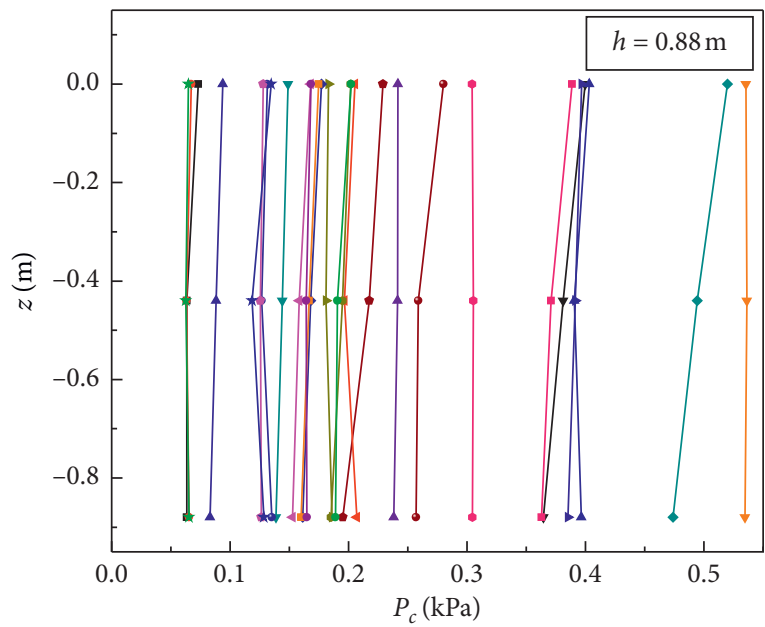

(c)

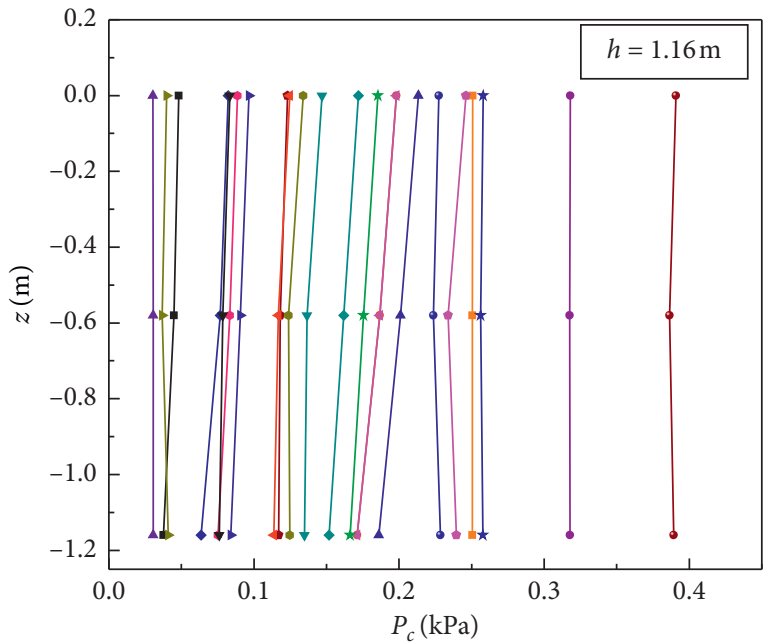

(e)

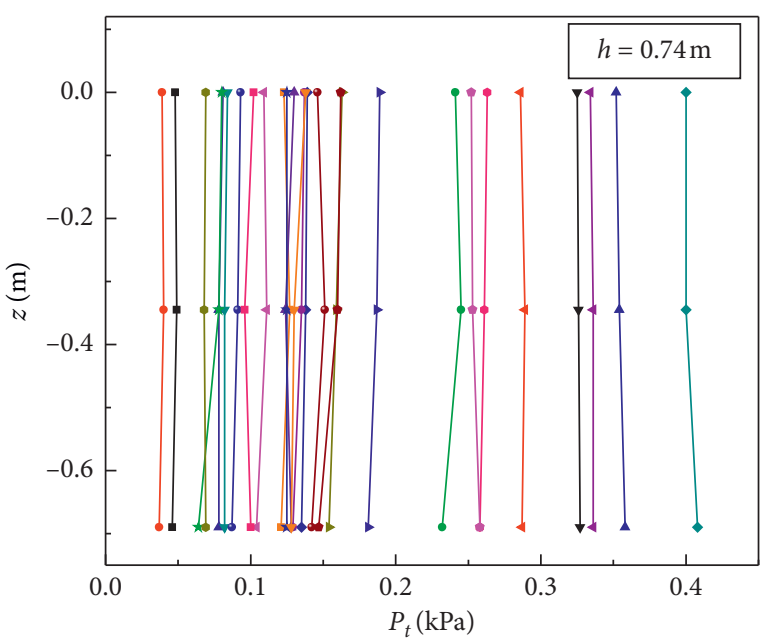

(b)

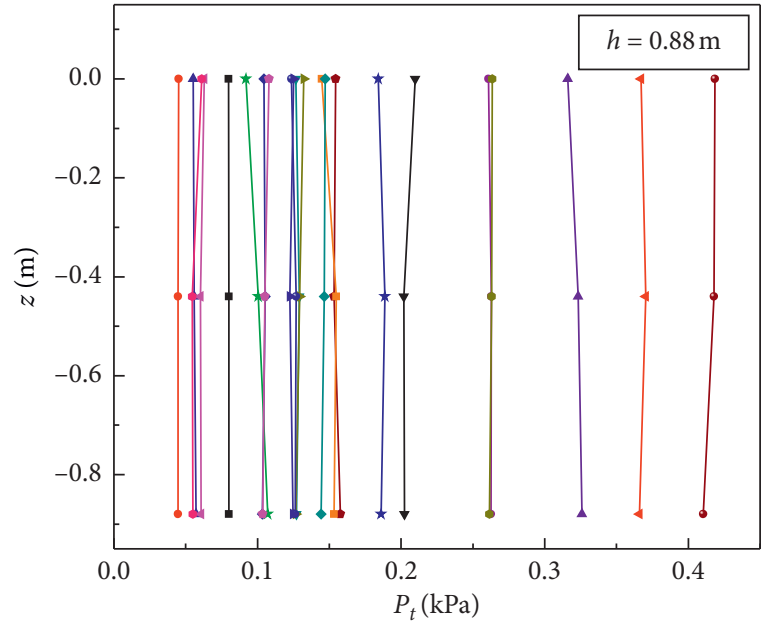

(d)

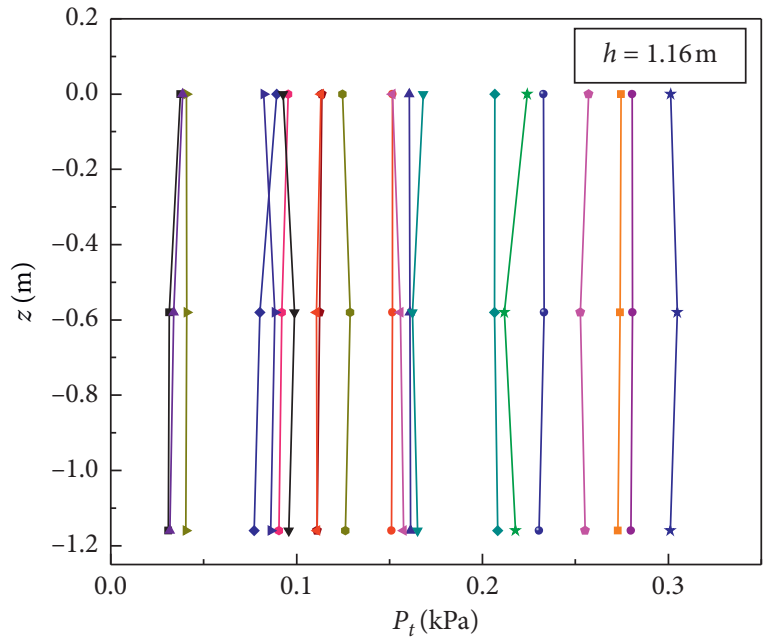

(f)

FIGURE 9: The distribution of wave pressure along water depth. 
top to bottom. The revealed distribution is consistent with Huang et al. [35]. It is not difficult to understand, the momentum of the landslide was converted into a huge impact pressure on the water as soon as the landslide entered into the water based on the conservation of momentum, and simultaneously the pressure can be transmitted along the water depth. With the propagation of waves, the dynamic pressure of the impulse wave decreased; however, the dynamic pressure was still constant against the pile from bottom to top. This finding could be supported by Heller [36], who reported that for shallow-water waves, e.g., landslide-generated impulse wave, the whole water body is in motion.

However, it is not strictly consistent with the "V" shape distribution proposed by Tan et al. [14]. For this distinction, it is largely attributed to the body in which the wave pressure sensor was put on. In Tan's test, the wave pressure sensors were put on the bank slope, which greatly influences the wave propagation from spreading and resulted in wave reflection, breaking, and runups. While in this study, the wave pressure sensors were placed on the front of the wharf pile, whereat waves can continue to propagate around the pile, which is also named "wave diffraction." Moreover, other piles without wave pressure sensors would affect the wave propagation and further affect wave pressure.

Now that the distribution characteristics of dynamic pressure have been revealed, the main affecting factors of wave pressure will be explored. The wave pressure was caused by the velocity component and the inertia component [37], so the relationship between dynamic pressure and wave amplitude and wave propagation velocity would be explored.

\subsection{The Dynamic Pressure and Force Acting on Wharf Pile}

3.3.1. The Relationship between Dynamic Pressure and Wave Amplitude. Given that the data of wave amplitude and dynamic pressure recorded by wave gauges (WG1, WG2, and WG3) and wave pressure sensors (WPS1, WPS2, and WPS3) were time series, which could be drawn as process curves. Test no. 69 was taken as an example to probe into the relationship between impulse wave pressure and wave amplitude. Figure 10 presents that the wave pressure fluctuation was synchronous as that of the fluctuation of water level elevation. To a large extent, the finding demonstrating the dynamic pressure was partly caused by the inertia component.

From the perspective of magnitude, based on the evolutionary consistency of wave pressure and amplitude described in Figure 10, it is further inferred that there may be a linear relationship between the impulse wave pressure and the wave amplitude. To support this claim, only the first wave crest amplitude $\left(a_{c}\right)$ and wave trough amplitude $\left(a_{t}\right)$ were analyzed. Because the first wave tends to have the greatest effect on the wharf piles, whilst it can effectively avoid the impact of wave reflection and superposition [38]. Similarly, the first maximum positive wave pressure $\left(P_{c}\right)$ and the first minimum negative wave pressure $\left(P_{t}\right)$ were selected. Scatter plots are adopted to study correlation between the wave amplitude and wave pressure at the same time (see Figure 11).

The experimental result of Figure 11 illustrates the relationship between the maximum wave amplitude and the

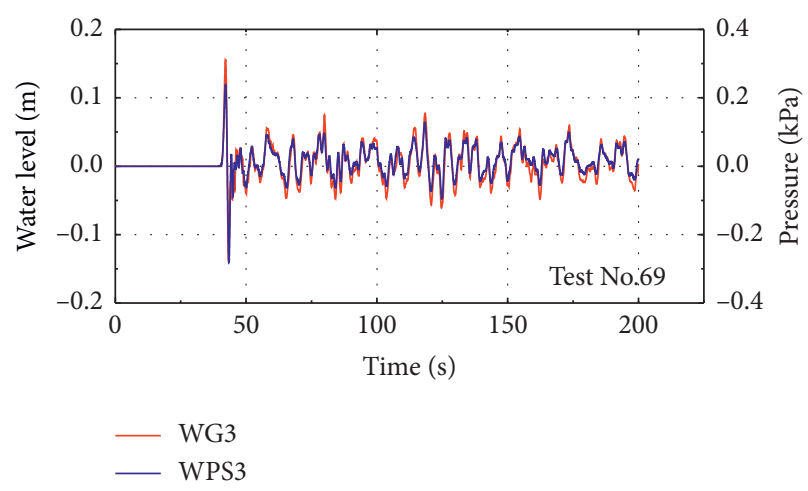

FIgURE 10: The curves of water surface elevation and impulse wave pressure from Test No. 69 with $l=1.0 \mathrm{~m}, w=1.0 \mathrm{~m}, s=0.6 \mathrm{~m}, h=$ $1.16 \mathrm{~m}$, and $\alpha=40^{\circ}$.

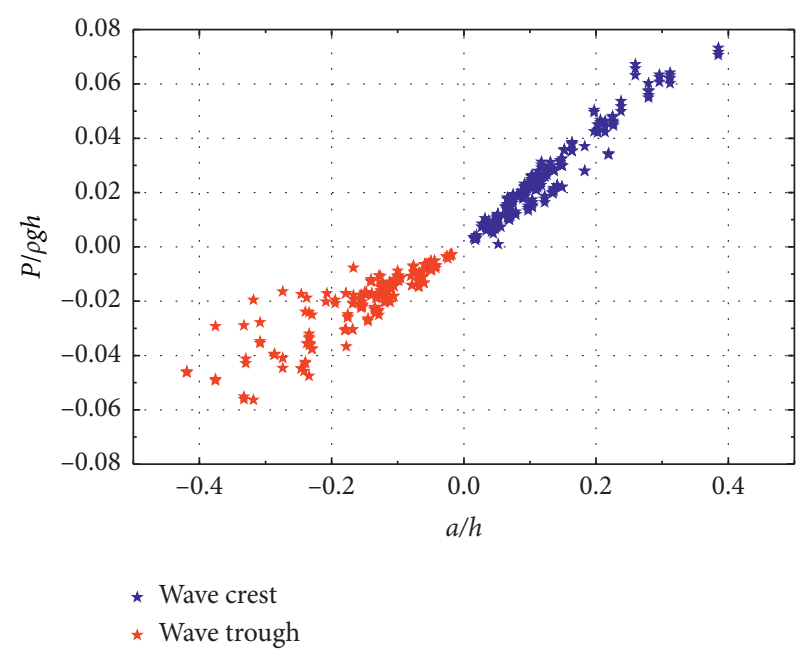

FIGURE 11: Relative wave pressure with respect to the relative wave amplitude.

maximum wave pressure. It was not difficult to find that there was a strong correlation between maximum positive wave pressure and maximum positive amplitude. Nevertheless, the minimum negative wave pressure scattered dispersedly with the maximum wave trough, especially the relative minimum negative wave pressure was more than a certain threshold value such as -0.02 .

\subsubsection{The Relationship between Dynamic Pressure and Wave} Propagation Celerity. The wave propagation celerity is an important parameter for the dynamic pressure as proposed by the standard of Code of Hydrology for Sea Harbour [37]. However, for each single crest and trough with an individual wave celerity [7], the relative propagation celerity of the first wave crest and wave trough was estimated, respectively, as shown in Figure 12.

In the present study, the crest velocity and trough velocity were defined by two neighbouring wave gauge spacing divided by the propagation time between the two successive wave crests or troughs and given as 


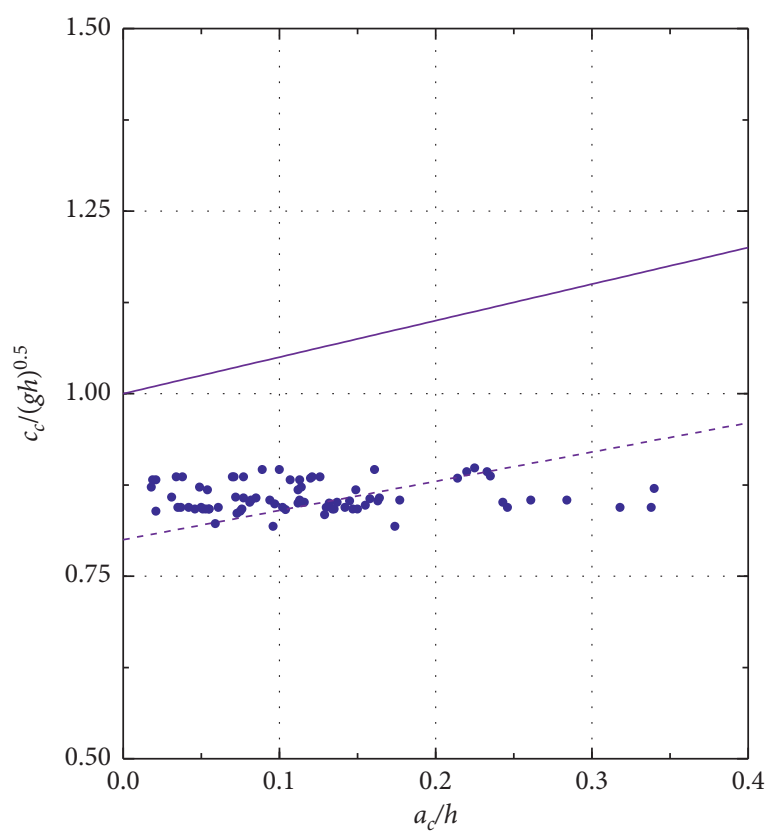

- Exp.

- The. -- $0.8^{*}$ The.

(a)

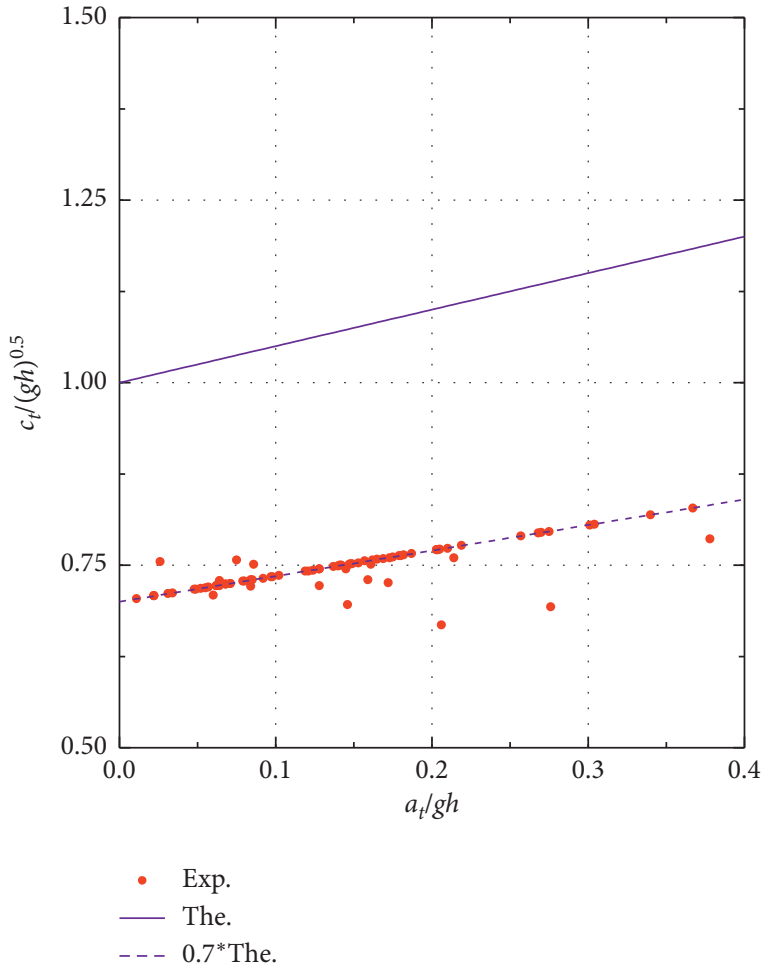

(b)

FIGURE 12: The relative wave propagation celerity. Exp. represents the experimental value. The. represents the theoretical value of the solitary propagation celerity.

$$
\begin{aligned}
& c_{c}=\frac{\Delta x}{\Delta t_{c}}, \\
& c_{t}=\frac{\Delta x}{\Delta t_{t}},
\end{aligned}
$$

where $c_{c}$ and $c_{t}$ are the first wave crest propagation celerity and the first wave trough propagation velocity, respectively. $\Delta t_{c}$ and $\Delta t_{t}$ are the propagation time required for the first crest and trough to pass the two successive wave gauges, respectively. $\Delta x$ indicates the distance between the locations of neighbouring wave gauges.

In Figure 12, it is not hard to find that the nondimensional wave propagation celerity could be described as a function of the dimensionless wave amplitude, and similar finding was also reported by Heller and Spinneken [39] and Tang et al. [32]. For the solitary, the celerity can be expressed as follows:

$$
\frac{c_{s}}{\sqrt{g h}}=1+\frac{a_{s}}{2 h}
$$

where $c_{s}$ is the solitary celerity, and $a_{s}$ is the solitary amplitude. The left side of equation (2) represents the relative wave celerity of the solitary, and the right side is a function of the relative amplitude.

The impulse wave propagation celerity was compared with a solitary propagation celerity. Based on our experimental results, the empirical formulas of $c_{c}$ and $c_{t}$ were expressed as follows:

$$
\begin{aligned}
& \frac{c_{c}}{\sqrt{g h}}=0.8\left(1+\frac{a_{c}}{2 h}\right), \\
& \frac{c_{t}}{\sqrt{g h}}=0.7\left(1+\frac{a_{t}}{2 h}\right) .
\end{aligned}
$$

It is noted that the amplitude used to calculate the landslide-generated impulse wave celerity was the mean wave crest and trough, which were evaluated based on the data recorded by WG2 and WG3. For equations (3) and (4), it is not difficult to find that in forms $c_{c}$ and $c_{t}$ were 0.8 and 0.7 times in terms of the form of the phase celerity of a solitary wave, which was due to the finding that landslidegenerated impulse waves consist of a wave packet propagating with a group celerity rather than a phase celerity, and the group celerity is commonly smaller than the phase celerity $[32,39]$. Furthermore, except for few values, the experimental wave trough was closer to the 0.7 times theoretical value more than the wave crest close to the 0.8 times theoretical one. It was attributed to the jetflow aforementioned in Section 3.1, whose effect on the experimental wave crest was greater than that on the wave trough.

In order to reveal the relationship between dynamic pressure and wave propagation celerity, the relative dynamic pressure and the relative wave propagation celerity of the wave crest and wave trough are shown in Figure 13.

Figure 13 shows that the relative dynamic pressure generated by the impulse wave was highly correlated with the relative wave propagation celerity, including the wave 


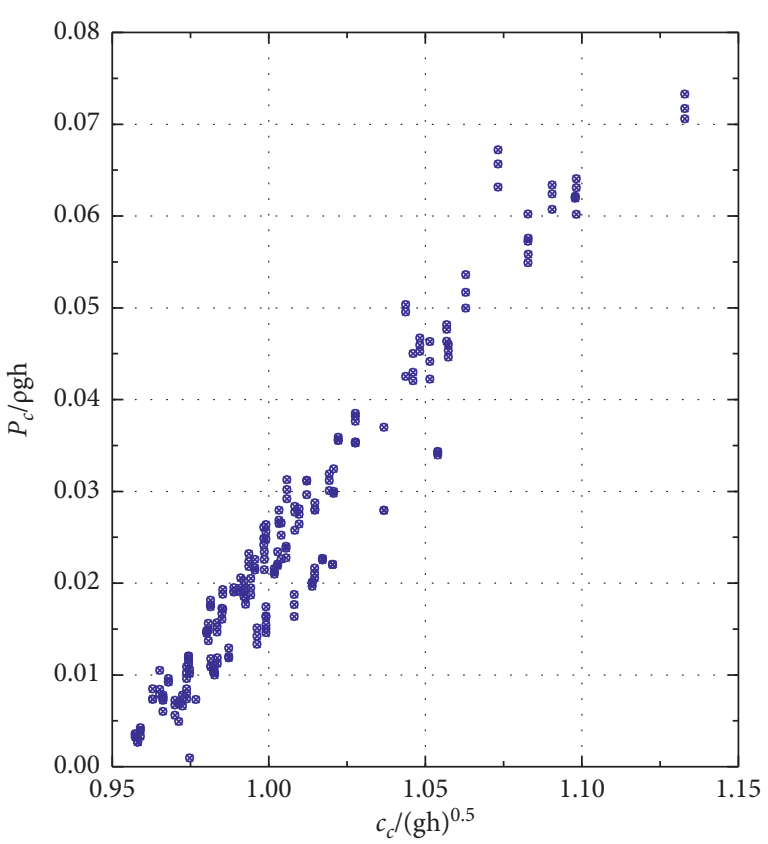

(a)

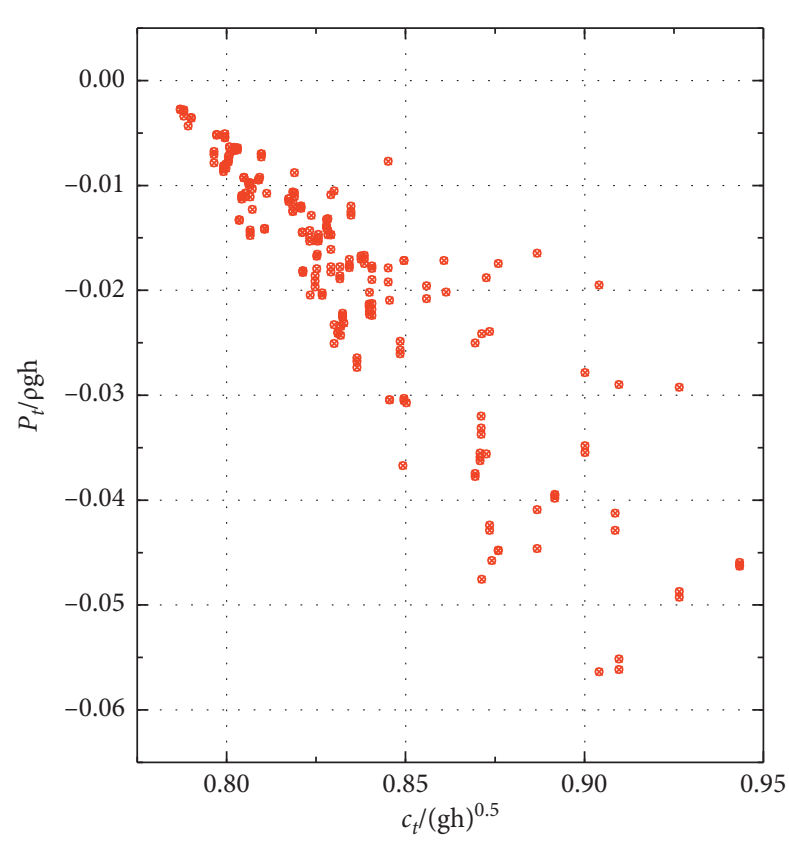

(b)

Figure 13: The relative dynamic pressure and the relative wave propagation celerity.

crest celerity and the wave trough celerity, and the dynamic pressure generated by the velocity component was clarified. Based on the aforementioned work, the dynamic pressure formula of impulse wave generated by landslide would be revealed in the subsequent work.

3.3.3. Dynamic Pressure Formulas of Impulse Waves. As previously mentioned, the dynamic pressure of impulse waves was related to the wave amplitude as well as wave propagation celerity, and as the wave crest amplitude is not always equal to the wave trough amplitude $[7,26,40]$ and the wave crest propagation celerity is also not the same as the propagation celerity of the wave trough, therefore, the positive dynamic pressure and the negative dynamic pressure were analyzed, respectively. In order to minimize the dimensional effect in the experiments, the multivariate dimensionless parameters were used; for instance, the dynamic pressure and wave amplitude were expressed as relative dynamic pressure and relative wave amplitude, respectively. The multiple-nonlinear regression method was used to analyze the experimental data, and the following functions could be obtained for the estimation of the positive and negative pressure acting on the wharf pile, as shown below:

$$
\begin{aligned}
& \frac{P_{c}}{\rho g h}=0.19\left(\frac{c_{c}}{\sqrt{g h}}\right)^{0.60}\left(\frac{a_{c}}{h}\right)^{0.98}, \\
& \frac{P_{t}}{\rho g h}=-0.14\left(\frac{c_{t}}{\sqrt{g h}}\right)^{-1.08}\left(\frac{a_{t}}{h}\right)^{0.98} .
\end{aligned}
$$

The coefficients of determination for these two equations are $R^{2}=0.89$ and $R^{2}=0.85$, respectively. As can be seen in these formulas, the dynamic pressures acting on the pile are estimated based on the relative wave amplitude and relative propagation celerity. In detail, the relative wave crest celerity $c_{c} / \sqrt{g h}$ or the relative wave trough celerity $c_{t} / \sqrt{g h}$ expressed the velocity component, and the relative wave amplitude $a_{c} / h$ or the relative wave trough $a_{t} / h$ represented the inertia component, which together influence the dynamic pressure. The validation ranges of the empirical equations (2) and (3) are $0 \leq P_{c} / \rho g h \leq 0.08$ and $-0.06 \leq P_{t} / \rho g h \leq 0$, respectively. To verify the formulas, the experimental values of the positive dynamic pressure and the negative one plotted versus the calculated are shown in Figures 14 and 15, and both the most experimental values scatter within a range of plus or minus $30 \%$.

It is not hard to find that the influence of celerity is larger for the troughs than for the crests in equations (5) and (6). In the tests, the relative celerity of the troughs span from 0.75 to 0.95 , and the relative celerity of the wave crests are from 0.95 to 1.15. Taking into account the influence and range of the wave celerity, the positive and negative dynamic pressures could be similar. Nevertheless, the relative amplitude is larger for the crests than for the troughs, and the constant coefficient in equation (5) is greater than that in equation (6). Therefore, positive dynamic pressures have a more important influence than the negative dynamic pressures.

3.3.4. Total Force Acting on Wharf Pile. It is well known that the total pressure is equal to hydrodynamic pressure plus hydrostatic pressure. For the hydrostatic pressure, it varies linearly along the vertical direction. However, the pile is cylindrical and symmetric, and then the hydrostatic pressures are equal in all directions and the force generated by the hydrostatic pressure is zero. The 


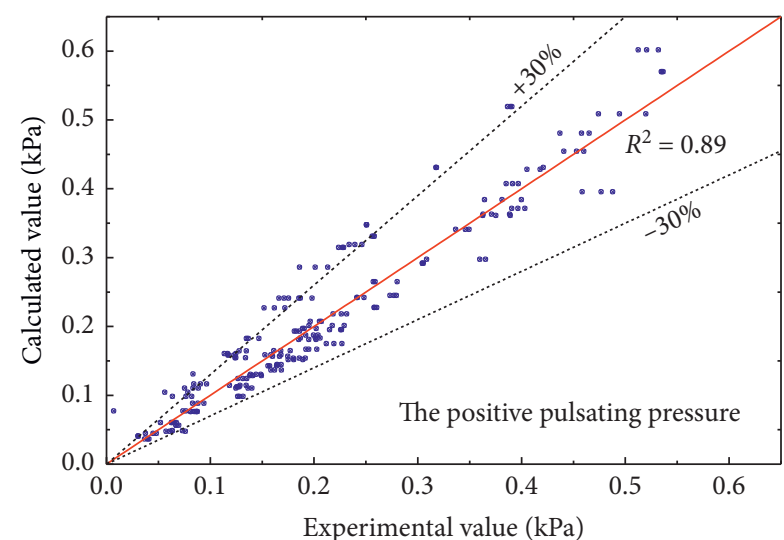

FIgURE 14: Experimental positive dynamic pressure versus calculated results.

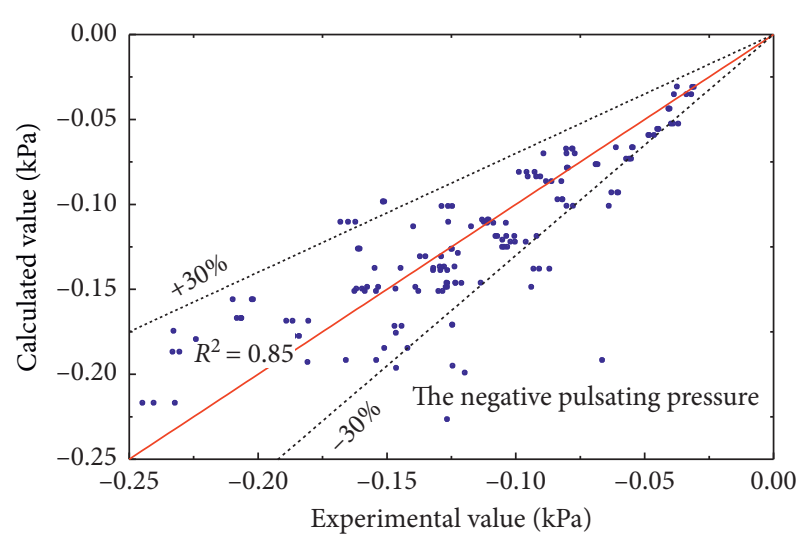

Figure 15: Experimental negative dynamic pressure versus calculated results.

hydrodynamic pressure is caused by the impulse wave when the water body is only disturbed by landslides, and it is equal to the dynamic pressure. It is noted that the impulse wave propagated in wave train, and the dynamic pressures are present around the pile, but their values are unequal because of the phase angle of the wave train. The profile of the dynamic pressure distribution on the pile is shown in Figure 16.

For the worst-case scenario that the pressure is assumed to have its maximum value, the total force is equal to the dynamic pressure times the bearing area, which could be expressed as

$$
A=(h+a) \times D,
$$

where $A$ and $D$ are the bearing area and diameter of the wharf pile, respectively. $a$ is the wave amplitude at the axis of the wharf pile. $a_{c}$ could be approximately used instead of $a$, and then formula (7) is expressed as

$$
A=\left(h+a_{c}\right) \times D .
$$

Therefore, the maximum positive force acting on wharf pile could be derived as follows:

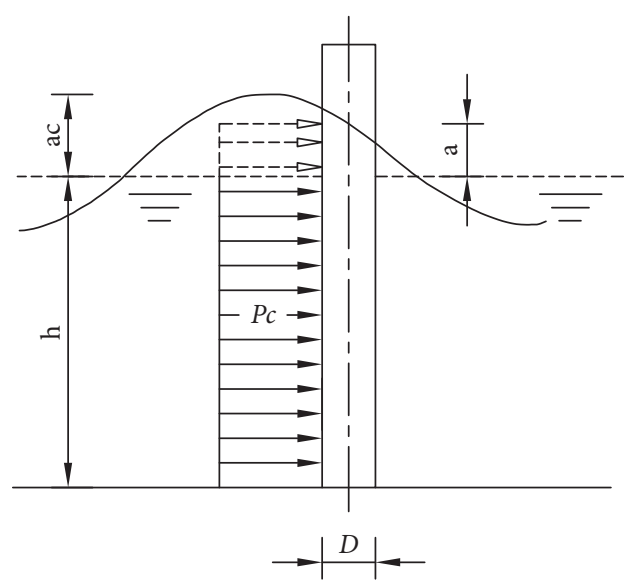

Figure 16: Sketch to define the force acting on the wharf pile.

$$
F_{\max }^{+}=0.19\left(\frac{c_{c}}{\sqrt{g h}}\right)^{0.60}\left(\frac{a_{c}}{h}\right)^{0.98} \rho g h \times\left(h+a_{c}\right) \times D .
$$

Similarly, the minimum negative force acting on wharf pile could be expressed as

$$
F_{\min }^{-}=-0.14\left(\frac{c_{t}}{\sqrt{g h}}\right)^{-1.08}\left(\frac{a_{t}}{h}\right)^{0.98} \rho g h\left(h-a_{t}\right) \times D .
$$

It should be noted that the proposed empirical formulas are applicable especially to the "high-pile," and they can provide reference for landslide-generated impulse wave disaster prevention and mitigation. Yet, the aforesaid dynamic pressure formulas were derived based on idealizations, simplifications, and specific test conditions. In our tests, the bottom of the basin was generalized as horizontal, and all the cross-sections were trapezoidal. In fact, the bottom of the natural river course is undulating and rough, and the cross-sections including not only trapezoid but also $\mathrm{U}$-shaped, $\mathrm{V}$-shaped, and other forms are always variable including even within a short river reach. These complex boundary conditions can affect the generation and characteristics of landslide-generated waves, which determine the dynamic pressure acting on the wharf pile. In addition, to simplify the physical model, the velocity related to the river flow is absent. However, the dynamic pressure acting on the wharf pile was more complicated under the action of water flow. Therefore, these results in this paper only provide a rough reference and are not applied to design the pile now. For further application to design wharf pile, a large number of extensive trials should be executed to address the universality of these formulas.

\section{Conclusions}

To effectively prevent the natural hazard of landslide-generated impulse waves in reservoirs, in this paper, we examined the impact of landslide-generated impulse waves against the wharf pile in the TGR. A series of physical experiments were conducted to generate impulse waves and study the impact of dynamic pressure on the wharf pile. On 
this basis, some conclusions are summarized and presented as follows:

(1) In terms of impulse wave characteristics, experimental results show that waves generated by landslide include jetflow and impulse wave. The jetflow appeared earlier than the impulse wave in time, and its amplitude was larger than the impulse wave amplitude. However, the propagation distance of the jetflow was shorter than the impulse wave, so the water affected by the jetflow was smaller. From a disastrous perspective, the jetflow had larger intensity but smaller range of influence.

(2) In terms of wave pressure exerted on the wharf pile, as the jetflow could not arrive at the wharf, the pressure was only induced by the impulse wave, and test results illustrate that the dynamic pressure was constant along the vertical direction.

(3) In terms of the dynamic pressure and force acting on the wharf pile, this study reports that the dynamic wave pressure was determined by the wave amplitude and wave celerity. A multiple regression was adopted to reveal the relationship between the dynamic pressure and the wave amplitude as well as wave celerity; furthermore, the corresponding force on the wharf pile caused by impulse wave was given.

\section{Data Availability}

The data used to support the findings of this study are included within the article.

\section{Conflicts of Interest}

The authors declare no conflicts of interest.

\section{Authors' Contributions}

Ping $\mathrm{Mu}$ and Pingyi Wang conceived the experiments and wrote the manuscript; Ping $\mathrm{Mu}$ and Linfeng Han designed and performed the experiments; Jie Zhang analyzed the data and drew pictures; Meili Wang recorded experimental data. All the authors modified and approved the submission of this manuscript.

\section{Acknowledgments}

This study was supported by the Chongqing Research Program of Basic Research and Frontier Technology (Grant no. cstc2017jcyjBX0070), the Science and Technology Research Program of Chongqing Municipal Education Commission (Grant no. KJQN201900718), and the National Natural Science Foundation of China (Grant nos. 51479015 and 52009014).

\section{References}

[1] J.-W. Zhou, F.-G. Xu, X.-G. Yang, Y.-C. Yang, and P.-Y. Lu, "Comprehensive analyses of the initiation and landslide- generated wave processes of the 24 June 2015 Hongyanzi landslide at the three Gorges reservoir, China," Landslides, vol. 13, no. 3, pp. 589-601, 2016.

[2] S. N. Ward and S. Day, "The 1963 landslide and flood at vaiont reservoir Italy. A tsunami ball simulation," Italian Journal of Geosciences, vol. 130, no. 1, pp. 16-26, 2011.

[3] P. Mu, P. Wang, L. Han, and C. Meng, "Review on research about disaster of landslide-generated impulse waves based on physical model experiment approach," Journal of Safety Science and Technology, vol. 16, no. 1, pp. 43-49, 2020.

[4] R.-S. Shih, W.-K. Weng, and C.-Y. Li, "Experimental study on the generation and attenuation of landslide tsunamis," Journal of Coastal Research, vol. 344, no. 4, pp. 864-876, 2018.

[5] F. M. Evers, W. H. Hager, and R. M. Boes, "Spatial impulse wave generation and propagation," Journal of Waterway Port Coastal and Ocean Engineering, vol. 145, no. 3, 2019.

[6] L. Han, Study on the Wave Field Characteristics of Impulse Waves Generated by Three-Dimensional Landslides in Curved Gorge-type Reservoirs, Chongqing Jiaotong University, Chongqing, China, 2019.

[7] H. M. Fritz, W. H. Hager, and H.-E. Minor, "Near field characteristics of landslide generated impulse waves," Journal of Waterway, Port, Coastal, and Ocean Engineering, vol. 130, no. 6, pp. 287-302, 2004.

[8] C. Shi, Y. An, and Q. Liu, "Landslide-generated impulse waves in deep V channel: runup and near field characteristics," Procedia Engineering, vol. 126, pp. 232-236, 2015.

[9] P. L.-F. Liu, T.-R. Wu, F. Raichlen, C. E. Synolakis, and J. C. Borrero, "Runup and rundown generated by three-dimensional sliding masses," Journal of Fluid Mechanics, vol. 536, pp. 107-144, 2005.

[10] B. C. McFall and H. M. Fritz, "Runup of granular landslidegenerated tsunamis on planar coasts and conical islands," Journal of Geophysical Research: Oceans, vol. 122, no. 8, pp. 6901-6922, 2017.

[11] F. M. Evers and R. M. Boes, "Impulse wave runup on steep to vertical slopes," Journal of Marine Science and Engineering, vol. 7, no. 1, 2019.

[12] P. Wang, L. Han, T. Yu, and C. Meng, "Effects of landslide generated impulse waves on ship impact force for pile wharf," Harbin Gongcheng Daxue Xuebao/Journal of Harbin Engineering University, vol. 37, no. 6, pp. 878-884, 2016.

[13] G. Dong, G. Wang, X. Ma, and Y. Ma, "Harbor resonance induced by subaerial landslide-generated impact waves," Ocean Engineering, vol. 37, no. 10, pp. 927-934, 2010.

[14] J.-m. Tan, B.-l. Huang, and Y.-b. Zhao, "Pressure characteristics of landslide-generated impulse waves," Journal of Mountain Science, vol. 16, no. 8, pp. 1774-1787, 2019.

[15] B. Yang, K. Yin, T. Xiao, L. Chen, and J. Du, “Annual variation of landslide stability under the effect of water level fluctuation and rainfall in the three Gorges reservoir, China," Environmental Earth Sciences, vol. 76, no. 16, p. 564, 2017.

[16] Y. Zhang, D. Li, L. Chen et al., "Numerical analysis of landslide-generated impulse waves affected by the reservoir geometry," Engineering Geology, vol. 266, 2020.

[17] Y.-p. Yin, B. Huang, X. Chen, G. Liu, and S. Wang, "Numerical analysis on wave generated by the qianjiangping landslide in three Gorges reservoir, China," Landslides, vol. 12, no. 2, pp. 355-364, 2015.

[18] B. Huang, Y. Yin, G. Liu, S. Wang, X. Chen, and Z. Huo, "Analysis of waves generated by Gongjiafang landslide in $\mathrm{Wu}$ Gorge, three Gorges reservoir, on November 23, 2008," Landslides, vol. 9, no. 3, pp. 395-405, 2012. 
[19] J.-w. Zhou, F.-g. Xu, X.-g. Yang, Y.-c. Yang, and P.-y. Lu, "Comprehensive analyses of the initiation and landslidegenerated wave processes of the 24 June 2015 Hongyanzi landslide at the three Gorges reservoir, China," Landslides, vol. 13, no. 3, pp. 589-601, 2016.

[20] B. Huang, Y. Yin, S. Wang et al., "A physical similarity model of an impulsive wave generated by Gongjiafang landslide in three Gorges reservoir, China," Landslides, vol. 11, no. 3, pp. 513-525, 2014.

[21] H. M. Fritz, W. H. Hager, and H.-E. Minor, "Landslide generated impulse waves," Experiments in Fluids, vol. 35, no. 6, pp. 505-519, 2003.

[22] G. Sælevik, A. Jensen, and G. Pedersen, "Experimental investigation of impact generated tsunami; related to a potential rock slide, western Norway," Coastal Engineering, vol. 56, no. 9, pp. 897-906, 2009.

[23] F. Enet and S. T. Grilli, "Experimental study of tsunami generation by three-dimensional rigid underwater landslides," Journal of Waterway, Port, Coastal, and Ocean Engineering, vol. 133, no. 6, pp. 442-454, 2007.

[24] P. Yuan, P. Wang, and Y. Zhao, "Model test research on the propagation of tsunamis and their interaction with Navigating ships," Applied Sciences, vol. 9, no. 3, p. 475, 2019.

[25] P. Yuan, P. Wang, Y. Zhao, and M. Wang, "Experimental study on the nonlinear behavior of a sailing container ship under landslide-induced surges," Advances in Civil Engineering, vol. 2019, Article ID 9081586, 11 pages, 2019.

[26] P. Mu, P. Wang, L. Han et al., "The propagation of landslidegenerated impulse waves and their impacts on the moored ships: an experimental investigation," Advances in Civil Engineering, vol. 2020, Article ID 6396379, 13 pages, 2020.

[27] B. Huang, Y. Yin, X. Chen, G. Liu, S. Wang, and Z. Jiang, "Experimental modeling of tsunamis generated by subaerial landslides: two case studies of the three Gorges reservoir, China," Environmental Earth Sciences, vol. 71, no. 9, pp. 3813-3825, 2014.

[28] B. Huang, L. Chen, X. Peng et al., "Assessment of the risk of rockfalls in Wu Gorge, three Gorges, China," Landslides, vol. 7, no. 1, pp. 1-11, 2010.

[29] L. Han and P. Wang, "Prediction of the maximum near-field wave amplitude of impulse waves generated by three-dimensional landslides based on momentum balance," Chinese Journal of Rock Mechanics and Engineering, vol. 37, no. 11, pp. 2584-2592, 2018.

[30] S. Viroulet, A. Sauret, and O. Kimmoun, "Tsunami generated by a granular collapse down a rough inclined plane," $E P L-$ Europhys LETT, vol. 105, no. 3, 2014.

[31] R. L. Wiegel, "Laboratory studies of gravity waves generated by the movement of a submerged body," Transactions, American Geophysical Union, vol. 36, no. 5, pp. 759-774, 1955.

[32] G. Tang, L. Lu, Y. Teng, Z. Zhang, and Z. Xie, "Impulse waves generated by subaerial landslides of combined block mass and granular material," Coastal Engineering, vol. 141, pp. 68-85, 2018.

[33] V. Heller, W. H. Hager, and H.-E. Minor, "Scale effects in subaerial landslide generated impulse waves," Experiments in Fluids, vol. 44, no. 5, pp. 691-703, 2008.

[34] D. Wüthrich, M. Pfister, I. Nistor, and A. J. Schleiss, "Experimental study on the hydrodynamic impact of tsunamilike waves against impervious free-standing buildings," Coastal Engineering Journal, vol. 60, no. 2, pp. 180-199, 2018.

[35] J. Huang, J. Lian, and T. Zhang, "Safety assessment on lechangxia dam under surge effect caused by landslide,"
Chinese Journal of Water Resources and Hydropower Engineering Analysis with Boundary Elements, vol. 44, no. 11, pp. 93-97, 2013.

[36] V. Heller, Landslide Generated Impulse Waves: Prediction of Near Field Characteristics, Eth Zurich, Zurich, Switzerland, 2007.

[37] JTS 145-2-2013, Code of Hydrology for Sea Harbour, China Communications Press, Beijing, China, 2013.

[38] Y. Wang, J. Liu, K. Yin, L. Yu, H. Zhou, and Z. Huo, "Comparison between the first and second wave crest amplitude generated by landslides," Ocean Engineering, vol. 171, pp. 71-77, 2019.

[39] V. Heller and J. Spinneken, "Improved landslide-tsunami prediction: effects of block model parameters and slide model," Journal of Geophysical Research: Oceans, vol. 118, no. 3, pp. 1489-1507, 2013.

[40] H. Xue, Q. Ma, M. Diao, and L. Jiang, "Propagation characteristics of subaerial landslide-generated impulse waves," Environmental Fluid Mechanics, vol. 19, no. 1, pp. 203-230, 2018. 